\title{
PROFITABILITY AND ECONOMICS OF CROPPING
}

\section{J.D. STEWART \\ Professor of Farm Management, Lincoln College}

The Data requirements for an assessment of the profitability of alternative farm management systems are the technical rates of substitution of one enterprise for another, and their price ratios. In a mixed arable system it is necessary to determine relative yields of cash crops, stocking rates and stock performance, and to assess the requirements -of these enterprises for variable and fixed resources. While the basis of analysis would usually be average yields and current or expected prices, it is often desirable to explore the effect of variation in the critical parameters.

Three methods of analysis are available, partial budgeting, including gross margins analysis, full comparative budgeting, and mathematical programming.

Partial analysis is appropriate where the alternatives being compared do not lead to any change in the fixed cost structure. Hence the analysis is carried out in terms of the direct revenue and costs only. Gross margins so derived are in widespread use by farm advisers as a valuable aid to farm management decision-making.

Where substantial changes in the resource structure are involved in any alternatives being analysed, it may be necessary to carry out full-scale budgeting. For example, in a mixed cropping situation, a land use system with its corresponding stock policy, labour and capital requirements would be established, and budgeted out against alternative systems. The procedure of comparative budgeting can clearly become quite laborious if there are more than two or three systems to appraise. In such a case there may be justification for using a mathematical technique which can be programmed for a computer. There has been some experience in applying linear programming to mixed farming problems in New Zealand (Stewart and Nuthall, 1966) but so far this has only been in basic investigational and research work, rather than in routine advisory work.

This paper is limited to a brief review of the relative profitability of cash crops under current prices, using gross 
margins as the basis of analysis. In most situations, gross margins per acre are of first importance, although, where operating capital or labour are most limiting, then it will be more appropriate to do the analysis in terms of gross margin per unit of capital or labour. These coefficients are usually more difficult to determine.

"Wheat versus sheep" has always been a key decision on Canterbury mixed arable farms. The first illustration, in Table 1, is therefore of gross margins of breeding ewe enterprises at two stocking rates, and for wheat at a range of yields, using current prices.

TABLE 1: GROSS MARGINS (1968 PRICES)

\begin{tabular}{lllll} 
& & & $\begin{array}{c}\text { Gross } \\
\text { Margin } \\
\text { \$peracre }\end{array}$ \\
\hline Breeding ewes at 4 per acre & $\ldots$ & $\ldots$ & $\ldots$. & 15 \\
Breeding ewes at 6 per acre & $\ldots$ & $\ldots$ & $\ldots$. & 25 \\
Wheat at 30 bushels $\ldots$. & $\ldots$ & $\ldots$ & $\ldots$. & 32 \\
Wheat at 50 bushels $\ldots$. & $\ldots$. & $\ldots$. & $\ldots$. & 57 \\
Wheat at 70 bushels $\ldots$. & $\ldots$. & $\ldots$ & $\ldots$. & 82 \\
\hline
\end{tabular}

For every 10 cent increase in the net price of wool, gross margins per acre for the sheep enterprises will improve by $\$ 4$ and $\$ 6$ per acre, respectively.

To get these figures in their full perspective, it would be reasonable to suggest that properties capable of running six ewes per acre would be also capable of consistent vields of 50 bushels of wheat. However, while surprisingly little is known about the full wheat-growing capacity of our soils, it is evident that, for a number of reasons, a cropping system cannot be based entirely on wheat. Alternative crops which are included in conventional systems in Canterbury have gross margins of the order shown in Table 2.

TABLE 2: GROSS MARGINS

\begin{tabular}{llccc} 
& & & & Price \\
& & Yield & $\begin{array}{c}\text { Gross } \\
\text { Margin } \\
\text { \$peracre }\end{array}$ \\
\hline Wheat &.. & $50 \mathrm{bu}$ & $1.35 / \mathrm{bu}$ & 57 \\
Peas &.. & $35 \mathrm{bu}$. & $1.60 / \mathrm{bu}$ & 39 \\
Barley &.. & $60 \mathrm{bu}$. & $0.85 / \mathrm{bu}$. & 38 \\
Linseed &.. & $18 \mathrm{cwt}$ & $60.00 / \mathrm{ton}$ & 46 \\
\hline
\end{tabular}


These gross margins are not strictly comparable, since the spring-sown crops provide winter and even early spring grazing where they follow grass, or stubble grazing where they follow other crops.

Where there are complementary relationships of this kind, a comparison of simple gross margins may be misleading. For example, there is strong technical complementarity between small seeds and sheep enterprises. In this case, it is not valid to isolate the small seeds crop for independent analysis. The problem can be handled by grouping related activities, or by deriving gross margins for the whole system. The following is an example of such an analysis carried out recently on an intensively cropped irrigation unit of 242 effective acres, on medium-light soils.

Two systems were considered. A, the existing one, comprised an intensive cropping and small seeds programme, with breeding ewes and fattening of bought-in store lambs. $B$ is a grass system with a pasture renewal programme through a winter feed crop; white clover is taken from second-year pastures. Yields and stocking rate budgeted are high, because of high fertility and skilful irrigation techniques.

The respective programmes and their total gross margins are given in Table 3.

Under system A, sheep were being stocked at 8 ewe equivalents per acre on the available spring grazing, the white clover and linseed areas also providing grazing over

TABLE 3: PROGRAMMES AND GROSS MARGINS OF TWO SYSTEMS

\begin{tabular}{|c|c|c|c|}
\hline & & $\begin{array}{c}A \\
\text { Crop System }\end{array}$ & $\begin{array}{c}B \\
\text { Grass System }\end{array}$ \\
\hline Winter feed & $\ldots$ & 一 & 26 \\
\hline Wheat $\quad \ldots$. & $\ldots$ & 39 & - \\
\hline Barley $\quad \ldots$. & $\ldots$ & 13 & - \\
\hline Peas $\quad \ldots$. & $\ldots$ & 26 & - \\
\hline Linseed .... & $\ldots$ & 13 & - \\
\hline White clover & $\ldots$ & 39 & 26 \\
\hline Lucerne $\ldots$. & $\ldots$ & 14 & - \\
\hline Pasture $\quad \ldots$. & $\ldots$ & 98 & 190 \\
\hline . & & 242 acres & 242 acres \\
\hline Ewes $\quad \ldots$. & $\ldots$ & 1,050 & 1,650 \\
\hline Store lambs & $\ldots$. & 400 & 400 \\
\hline Gross margin $(\$)$ & $\ldots$ & 13,040 & 10,400 \\
\hline
\end{tabular}


this bottleneck period. All lambs from the 1,050 ewes were fattened, then store lambs were bought-in for fattening on summer-autumn irrigated grass and stubbles. Sheep were wintered on lucerne hay, header tailings and autumnsaved pasture. It is a beautifully integrated system. It is this high level of complementarity which accounts for what may appear to be a disparity in the relative stock carrying capacities of the two systems.

It must be noted that the difference of approximately $\$ 2,600$ in total gross margins leads to the same absolute difference in net profit before taxation, so that, after deducting fixed costs, this is a substantial difference. It should also be noted that an improvement of 10 cents per $\mathrm{lb}$ for wool would reduce the difference by $\$ 600$.

Clearly there are some limitations to "gross margin per acre" as the final criterion of profitability. For instance, it may be necessary to examine the likely effect of changes indicated by gross margins analysis on the capital and labour requirements.

In general, when comparing an intensive cropping system with a sheep system, it will be found that the fixed capital requirements may not vary significantly. Capital involved in the additional stock may even exceed the reduced investment in plant. For instance, in the example cited above, if it is assumed that the clover heading in system $\mathrm{B}$ is done by contract, the only difference in plant would be a header. To be measured against this there is the additional investment in 600 ewes. With repect to operating capital requirements, a mixed cropping system will usually result in a better spread of revenue, and therefore a more attractive operating capital profile. Furthermore, some additional flexibility of financial management is possible, particularly where bulk storage facilities are installed. Also, the small seeds producer, if he has reasonable financial liquidity, has scope for manipulating his stocks.

There is no evidence that mixed cropping systems require more labour than sheep systems. Intensity of production within the system would appear to be a more important determinant of labour requirement than the system itself. There will, of course be different labour bottlenecks. In the intensive mixed cropping system it will be in the harvest and immediate post-harvest period. Mixed cropping farmers are generally able to meet this constraint by employment of casual labour. Apart from this, the spread of work in a well-balanced cropping system is good. 
An additional important criterion in assessing the economics of a farming system is risk and uncertainty. Although, again, there is very little research in this field (McArthur, 1969), it is clear that there is a higher degree of technical risk with individual enterprises in a mixed cropping system. These risks relate mainly to climatic and disease factors during the growing period, and at harvest. However, these risks are minimized by farmers who have high standards of cultural practices, and whose soil fertility levels are high. As in all types of farming, the good managers seem to have the most "luck". There is also considerable risk involved with prices, particularly for small seeds, and other crops for which guaranteed or contract prices are not available, but these are no greater than for wool and lamb. Furthermore, since prices for the various products of mixed cropping farms are influenced by a number of unrelated factors, there are often compensatory movements.

The ability of the New Zealand farmer to remain economically viable in the face of the continuous decline in his terms of trade in the last decade has been based on technical and management progress. In the intensive grassland areas it has been the stocking rate revolution, on hill country the breaking of the soil fertility barrier. In the mixed cropping areas of Canterbury something comparable is happening, pioneered not by research centres, but by aggressive extension and imaginative farmers. The basic principle is the same, high rates of buildup of stock-induced fertility. But in this case the fertility is exploited by crop production rather than by additional stock. On conventional cropping soils, this is resulting in an intensification of cropping practices, a general tightening up of crop sequences and minimization of low gross margin practices-e.g., fallows, special fattening crops, lucerne for hay, grazing pastures. On soils previously regarded as marginal for cropping, profitable cropping practices are being adopted.

The crucial management decision relates to the minimum length of pasture life necessary to ensure fertility maintenance, and the length of the cropping sequence. Farmer experience indicates that, if stocking rates of 8 to 10 ewes are adopted on the available spring-summer grazing, and if winter stocking prior to the sowing of spring crops is also at high levels, only two years of pasture may be necessary.

The following are examples of crop sequences recently observed which are proving culturally possible, and which 
are yielding high per acre outputs, in the range of $\$ 70$ to $\$ 85$ per acre. Their major attribute is the efficiency of land use, and the high degree of complementarity between crop and livestock enterprises which is achieved.

\section{On Good Medium-heavy SoIls}

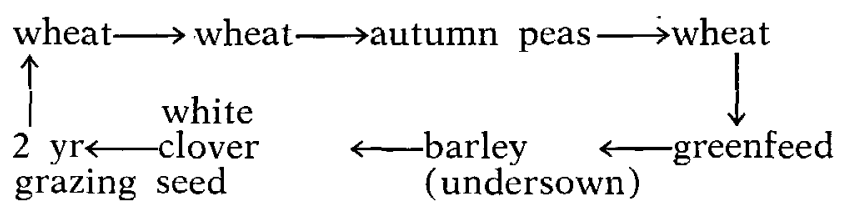

2. ON Light Solls, 35 to 40 IN. Rainfall

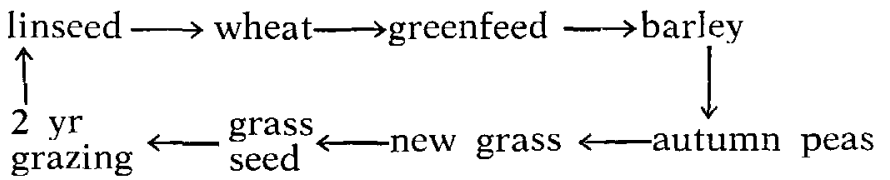

3. ON Light-MEdiUM SoILS, Low RAINFALL

early turnips $\longrightarrow$ wheat $\longrightarrow$ barley

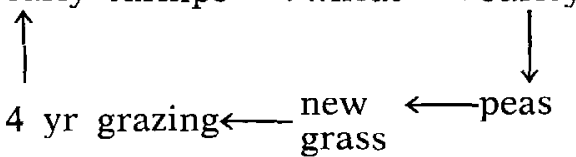

4. ON Light-MEdium SoIls, IRRigated

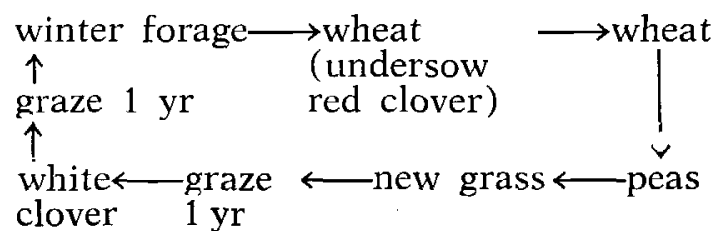

\section{CONCLUSION}

There is considerable scope for the intensification of profitable cropping sequences on a wide range of soil types in Canterbury. The principle of high fertility turn-round through heavy stocking on available grazing, and the general tightening up of crop sequences which this permits is leading to high physical and financial performance. Further developments at present being explored include the use of artificial nitrogen, the incorporation of cattle 
enterprises into the management systems, and the widespread use of irrigation on crops. Where soil and moisture conditions permit good crop yields, it would require extremely high stocking rates, and low cost systems, as well as an improvement in wool prices, to make sheep competitive.

This paper has neglected a vital matter. It has been concerned only with the individual farmer, and not with the aggregative effects of many farmers making the same decisions. The elasticity of demand for some of the products discussed above is low, and, for those which have only a domestic market, growth in demand may only be comparable to population growth. Important though the aggregative problems are, they are beyond the scope of this paper. The farm management problem is to develop profit maximizing strategies in the light of current and expected prices in the short run. Progressive mixed cropping farmers are exploiting present technology and prices fully, and are always ready to adapt management quickly to meet changes in these factors.

\section{REFERENCES}

McArthur, A. T. G., 1969: Diversification, risk and mixed cropping. N.Z. agric. Sci. In press.

Stewart, J. D.; Nuthall, P. L. 1966: Programming a Canterbury mixed farm. A.E.R.U. Pub. No. 6. Lincoln College. 
ECONOMICS OF CROPPING

\section{APPENDIX}

\section{1: GROSS MARGINS}

\begin{tabular}{|c|c|c|c|c|c|c|c|c|}
\hline \multicolumn{9}{|l|}{ WHEAT } \\
\hline Price $(\$)$ & $\ldots$ & $\ldots$ & $\begin{array}{c}30 \mathrm{bu} . \\
1.35\end{array}$ & & $\begin{array}{r}50 b u \\
1.35\end{array}$ & & $\begin{array}{c}70 \mathrm{bu} . \\
1.35\end{array}$ & \\
\hline Gross revenue & $\ldots$ & $\ldots$ & & 40.50 & & 67.50 & & 94.50 \\
\hline \multicolumn{9}{|c|}{ Direct costs: } \\
\hline Cultivation & $\ldots$ & $\ldots$ & 0.90 & & 0.90 & & 0.90 & \\
\hline Seed & $\ldots$ & $\ldots$ & 3.77 & & 3.77 & & 3.77 & \\
\hline Heading & $\ldots$ & $\ldots$ & 0.10 & & 0.13 & & 0.20 & \\
\hline Sacks & $\cdots$ & $\cdots$ & 1.10 & & 1.87 & & 2.53 & \\
\hline Cartage & $\cdots$ & $\cdots$ & 1.50 & & 2.55 & & 3.45 & \\
\hline Levy & $\ldots$ & $\ldots$ & 0.41 & & 0.69 & & 0.96 & \\
\hline \multirow[t]{2}{*}{ Other } & $\cdots$ & $\cdots$ & 0.10 & & 0.10 & & 0.10 & \\
\hline & & & & 7.88 & & 10.01 & & 11.91 \\
\hline Gross margin & $\cdots$ & $\ldots$. & & $\$ 32.62$ & & $\$ 57.49$ & & $\$ 82.50$ \\
\hline
\end{tabular}

\section{SHEEP}

Gross revenue per ewe:

$\begin{array}{lllr}1.1 \mathrm{lambs} \text { at } \$ 4.20 \ldots . & \ldots . & \$ 4.62 \\ 10 \mathrm{lb} \text { wool at } 25 \mathrm{c} \text { net } & \ldots . & 2.50\end{array}$

$\$ 7.12$

Direct costs:

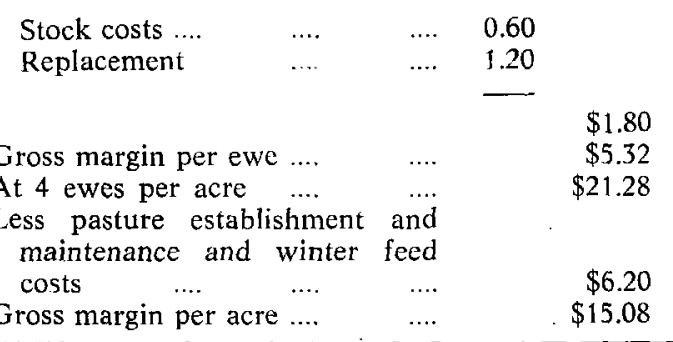

\section{2: GROSS MARGINS}

\begin{tabular}{|c|c|c|c|c|c|c|}
\hline & & & Wheat & Peas & Barley & Linseed \\
\hline Yield & $\ldots$ & $\ldots$ & 50 & 35 & 60 & 18 \\
\hline Price & $\ldots$ & $\ldots$ & 1.35 & 1.60 & 0.85 & 60.00 \\
\hline Gross revenue & $\ldots$. & $\ldots$ & 67.50 & 56.00 & 51.00 & 55.80 \\
\hline Direct costs .... & $\ldots$ & $\ldots$ & 10.01 & 17.40 & 13.02 & 9.80 \\
\hline Gross margin & $\ldots$ & $\ldots$ & 57.49 & 38.60 & 38.00 & 46.00 \\
\hline
\end{tabular}


3: GROSS MARGINS

\begin{tabular}{|c|c|c|c|c|c|}
\hline & & Units & Yield & $\begin{array}{c}G . M \\
\text { per unit } \\
\$\end{array}$ & $\underset{\$}{G . M}$ \\
\hline \multicolumn{6}{|l|}{ CROP SYSTEM } \\
\hline Wheat & $\ldots$ & 39 & 70 & 76 & 2,964 \\
\hline Barley $\quad \ldots$. & $\ldots$ & 13 & 80 & 53 & 689 \\
\hline Peas & $\ldots$ & 26 & 50 & 40 & 1,040 \\
\hline Linseed $\quad \ldots$. & $\ldots$ & 13 & 30 & 79 & 1,027 \\
\hline White clover & $\ldots$ & 39 & 320 & 45 & 1,755 \\
\hline Pasture $\quad \ldots$. & $\ldots$ & 137 & & -6.20 & -849 \\
\hline Lucerne .... & $\ldots$ & 14 & & -9.00 & -126 \\
\hline Hay $\quad \ldots$. & $\ldots$ & & & & -200 \\
\hline Rape & $\ldots$ & 26 & & -4.00 & -104 \\
\hline Ewes & $\ldots$ & 1,050 & & 5.90 & 6,195 \\
\hline Lambs $\quad \ldots$. & $\ldots$. & 400 & & 1.50 & 650 \\
\hline Total gross & margin & & & & $\$ 13.041$ \\
\hline
\end{tabular}

\section{GRASS SYSTEM}

\begin{tabular}{lrrrrrr} 
White clover & $\ldots$. & 26 & 320 & 45 & 1,170 \\
Ewes & $\ldots$. & $\ldots$. & 1,650 & & 6.30 & 10,395 \\
Lambs & $\ldots$ & $\ldots$. & 400 & & 1.80 & 720 \\
Pasture & $\ldots$. & $\ldots$. & 202 & & -6.20 & $-1,252$ \\
Lucerne & $\ldots$. & $\ldots$. & 14 & -9.00 & -126 \\
Hay & $\ldots$. & $\ldots$. & & & -400 \\
Rape & $\ldots$. & $\ldots$. & 26 & & -4.00 & -104 \\
Total gross & margin & & & & $\$ 10,403$ \\
\hline
\end{tabular}

\section{DISCUSSION}

Asked for comments on specialization as against diversification of farming systems, Stewart said that he considered that specialization had advantages in that skills in a narrow range were developed more rapidly and led to a higher performance.

Replying to a statement that the cropping rotations he had outlined were very dependent on wheat and that there could be serious consequences if wheat prices should fall, Stewart considered that wheat could fall significantly in price and still be more profitable than sheep. In fact, he thought wheat would still be more profitable at one dollar a bushel than sheep at the prices obtaining at present. 